See discussions, stats, and author profiles for this publication at: https://www.researchgate.net/publication/321349274

\title{
Smart cities, epistemic communities, advocacy coalitions and the 'last mile' problem
}

Article in it - Information Technology · November 2017

Dol: 10.1515/itit-2017-0004

5 authors, including:

\section{Rob Kitchin}

National University of Ireland, Maynooth

293 PUBLICATIONS 10,025 CITATIONS

SEE PROFILE
Leighton Evans

Swansea University

52 PUBLICATIONS 218 CITATIONS

SEE PROFILE

Some of the authors of this publication are also working on these related projects:

Project The Programmable City View project

Project Building City Dashboards View project 


\section{Rob Kitchin*, Claudio Coletta, Leighton Evans, Liam Heaphy, and Darach MacDonncha Smart cities, epistemic communities, advocacy coalitions and the 'last mile' problem}

https://doi.org/10.1515/itit-2017-0004

Received May 24, 2017; revised October 20, 2017; accepted October 29, 2017

\begin{abstract}
We argue that the ideas, ideals and the rapid proliferation of smart city rhetoric and initiatives globally have been facilitated and promoted by three interrelated communities: (i) 'urban technocrats'; (ii) a smart cities 'epistemic community'; (iii) a wider 'advocacy coalition'. We examine their roles and the multiscale formation, and why despite their influence they encounter a 'last mile problem'; that is, smart city initiatives are yet to become fully mainstreamed. We illustrate this last mile problem through a discussion of plans to introduce smart lighting in Dublin.
\end{abstract}

Keywords: Smart cities, epistemic community, advocacy coalition, technocrats, urban governance, city administration, smart lighting.

ACM CCS: Social and professional topics $\rightarrow$ Professional topics $\rightarrow$ Computing and business $\rightarrow$ Socio-technical systems, Social and professional topics $\rightarrow$ Computing/technology policy $\rightarrow$ Government technology policy, Social and professional topics $\rightarrow$ Computing/technology policy $\rightarrow$ Commerce policy

\section{Introduction}

Over the past decade, many cities have adopted policies and rolled out programmes and projects designed to transform them into a 'smart city'. It is clear from the plethora of initiatives underway globally that the idea and ideals of smart cities are quite broadly conceived, with enterprises ranging from those: aimed at changing the nature

\footnotetext{
*Corresponding author: Rob Kitchin, NIRSA, Maynooth University, Iontas Building, W23 F2H6, Maynooth, Ireland, e-mail: rob.kitchin@nuim.ie

Claudio Coletta, Liam Heaphy, Darach MacDonncha: NIRSA, Maynooth University, Iontas Building, W23 F2H6, Maynooth, Ireland Leighton Evans: Media and Communications, Swansea University, SA2 8PP, Swansea, Wales, United Kingdom of Great Britain and Northern Ireland
}

of urban regulation and governance through the use of data-driven systems that make the city knowable and controllable in new, dynamic, reactive ways; to digital systems that improve the efficiency and effectiveness of city services, increase the economic productivity, competitiveness and innovation of businesses, and drive economic growth and urban development; to ICT-enabled schemes that enhance environmental sustainability and urban resilience; to technology-led approaches that improve quality of life and promotes a citizen-centric model of development which fosters social innovation, civic engagement and social justice [14, 21]. Critically, in all these cases, digital technologies are front-and-centre as a vital ingredient for addressing the major issues facing city managers, urban citizens, and industry leaders.

Accompanying and facilitating the movement towards the creation of smart cities is the rise of a new set of urban technocrats (e.g., chief innovation/technology/data officers, project managers, consultants, designers, engineers, change-management civil servants, and academics), supported by a range of stakeholders (e.g., private industry, lobby groups, philanthropists, politicians, civic tech bodies), events (e.g., various smart city expos, workshops, hackathons), and governance arrangements (e.g., smart city advisory boards). Indeed, within a relatively short period of time a dense network of new positions and institutional bodies have been created that, on the one hand conceive and produce smart city technologies and initiatives, and on the other seek to roll-out and embed these enterprises within city institutions and change the policy, organisational, resourcing, and regulatory urban landscape. This network interlinks a diverse set of stakeholders from across government, NGOs, industry and academia, which is convinced of the benefits of making cities 'smart'. This network works to spread the 'gospel' of smart city rhetoric and convert city leaders to its mission. Once grounded in a locale, the aim is to translate the mission into action and realisation through the creation of a new urban growth regime, with allied stakeholders working in concert to actualize the smart city.

In this paper, we examine this new set of urban technocrats, their various roles, and the professional networks and apparatus that support them in their work. We argue that collectively these technocrats draw from, work 
with, and in some cases belong to, a new smart city epistemic community - that is, a network of knowledge and policy experts that share a worldview and a common set of normative beliefs, values and practices with respect to an issue and help decision-makers identify and deploy solutions to solve problems [12]. We then detail how this epistemic community intersects with a wider set of smart city interest groups to form an 'advocacy coalition' [18] that works at different scales - global, supra-national, national, local - to spread its rhetoric and mission, providing a number of examples of smart city communities and coalitions at each scale. In the final section, we consider the translation of the ideas and practices of this advocacy coalition into the policies and work of city administrations. In particular, we consider the reasons why smart city initiatives are yet to become fully mainstreamed.

\section{The new technocrats}

A decade ago, there were few professionals in any stakeholder group (city administrations, industry, academia) who would prefix their title with the words 'smart city' (e.g., 'smart city coordinator', 'smart city project manager', 'smart city consultant'). Moreover, within city administrations there would have been hardly any CIOs (Chief Information Officer - a senior executive officer responsible for IT, including operations and strategy), CTOs (Chief Technology Officer - a senior executive focused on science and technological developments in an organization, including research and development), or CDOs (Chief Data Officer - an executive position responsible for the governance and use of data across an organization); posts that are presently strongly aligned to the smart city mission in those cities that have appointed them. To be sure, there were a plethora of people employed by city administrations charged with using IT to deliver city services and to manage and make sense of city data (e.g., IT staff, GIS officers, control room operators), but their roles were quite specific and did not form part of an overarching city management strategy. Over the past decade, the situation has changed in many cities, with city administrations employing new technical, operational and policy staff aligned to a smart city agenda. Such staff include those 'smart city' and 'chief' posts mentioned above, plus data coordinators/managers, data scientists, designers, policy specialists, software engineers, and IT project managers. Many of these new technocrats are recruited from industry or academia, seeking to bring specialist knowledge and skills into an organisation, and act as new 'institutional entrepreneurs' [23] driving in- ternal change in how city administrations use data and technology.

These staff occupy roles in existing departments and units, but also populate new units. For example, in Dublin there is Dublinked, responsible for open data, and Smart Dublin, that coordinates smart city initiatives. Together they form a single operational unit. Interestingly, the unit is co-owned across four local authorities (LAs), with members of staff seconded to the unit, and two staff members from each LA sitting on the steering group, with the unit reporting to the CEOs of the four LAs. In the City of Boston new units include the Citywide Analytics team (who monitor and analyse the performance of all the departments and city services in the organisation), an open data team, and New Urban Mechanics (who create new apps and services for citizens and the organization). Often a specialist smart city unit, due to its crosscutting remit, is located within the Mayor's office. In some cases, the new appointments and units accompany wider structural change within the organization as it re-orientates around new modes of corporate governance, procedures, priorities, and policies. The introduction of a CIO and/or CTO/CDO is often accompanied by internal restructuring of roles, responsibilities and reporting lines, for example. Within these new structures, smart city technocrats often span departmental silos, coordinating technical approaches to service delivery across an organisation (not just IT infrastructure and software) and often extensively liaise and collaborate with, and procure services from, other stakeholders.

In addition, there has been a large growth in consultancies offering specialist smart city services, employing a raft of new smart city 'experts' that provide advice, research, training, and a range of related business services with respect to potential solutions, policy formulation, procurement, tracking outcomes, etc., along with new smart city marketers and sales teams. Similarly, tech companies have sought to engage with city administrations to enter in public-private arrangements, sell new products, work jointly with cities on the testbedding of innovations, and to shift mind-sets about how to tackle particular issues. Likewise, academics have been actively engaging with cities on applied, interdisciplinary research concerning urban issues, often in partnership with industry. Indeed, there is a boom in smart cities and urban science research underway globally, with a number of large new, interdisciplinary research centres being established, often funded through research agencies and matching industry investment $[1,22]$. 


\section{A new epistemic community and advocacy coalition}

This rapidly growing set of smart city professionals within city administrations, governments (local, national, supranational), NGOs, industry, and academia suggests that a new smart cities epistemic community has been formed over the past decade. In his seminal work, Peter Haas [12] defined an epistemic community as a 'network of professionals with recognised expertise and competence in a particular domain and an authoritative claim to policy relevant knowledge within that domain or issuearea.' Such a community of knowledge-based experts help decision-makers identify and define the problems they face along with possible policy solutions, and also to assess policy outcomes. Haas details that epistemic communities share a set of knowledge, normative and casual beliefs, and practices, and work in common action to forward a particular vision and policy response [12]. They seek to provide contextual framing, advice and social learning to navigate a complex and uncertain social-economic political landscape [5], and exercise influence through their claims to insightful and authoritative knowledge that has high utility for decision- and policy-makers who maybe lacking sufficient expertise to make informed choices [13]. Importantly, Haas [12] argues that they differ from interest groups or policy networks through their claim to authoritative expertise. That said, in general terms, epistemic communities are not necessarily composed of technical and theoretical knowledge experts: they can also emerge from communities of practice which connect experience and practical knowledge, such as 'expert amateurs' and communities engaged in 'citizen sensing' and peer-to-peer collaboration $[10,20]$. The community operates and grows through social learning (teaching others their ideas) and professional networking (through working arrangements, workshops, conferences, etc.).

Given that in general terms smart city professionals claim and are often given authoritative voice, share a set of knowledge, beliefs, practices, and aim to craft a particular vision and policy response to urban issues, it thus seems fair to conclude that they constitute an epistemic community. That said, it is also the case that there is a blurred line between a smart city epistemic community and smart city vested interest groups. The two overlap with respect to how they think urban issues should be addressed through technological solutions, and they work in concert to form an 'advocacy coalition' - that is, a coalition of 'people from a variety of positions (elected and agency officials, interest group leaders, researchers) who share a particular be- lief system' and 'who show a non-trivial degree of coordinated activity over time' [18: 25]. However, while theoretically an epistemic community does not have direct pecuniary incentives to seek to shape the policy landscape, being driven by normative beliefs, some elements of advocacy coalitions are also motivated by a desire to provide solutions and generate profit. In the latter case, not only is substantive policy advice (means) and policy proposals (ends) being proffered (usually for a hefty fee), but a pathway to a particular solution usually provided by private enterprise [5]. As such, the kinds of advice given by tech/consultancy companies, such as IBM, is far from impartial and not simply rooted in authorative knowledge expertise, a particular technical approach, and a belief in the power of technology as the most effective way to run cities and fix urban problems. That said, epistemic communities are also clearly driven by self-interest - to see their ideas implemented and to control a policy domain. With respect to the smart city, an epistemic community and advocacy coalition is evident at four scales: global, supra-national, national and local.

\subsection{Global epistemic community and advocacy coalition}

In just a handful of years, a number of sizable global smart city consortia have been formed consisting of aligned actors who share a common vision with regards to how cities should be managed and urban issues addressed. Each consortium makes claims to provide city administrations with authorative, neutral, expert advice, resources, and partnerships that can cut through the complexities of managing cities to provide guidance on how to use digital technologies to solve difficult issues/problems.

For example, the 'Smart City Council' (SCC; http:// smartcitiescouncil.com/) is a coalition of partners strongly advocating for the adoption of smart city policy and interventions. The SCC consists of 21 'Lead Partners' (including IBM, Cisco, SAS, Schneider Electric, Deloitte, Oracle; Microsoft), 21 'Associate Partners' (including Intel, Huawei, Siemens, Panasonic), and 70 'Advisors' (including the Institute of Electrical and Electronics Engineers (IEEE), International Finance Corporation (part of the World Bank), International Organization for Standardization (ISO), International Telecommunication Union (ITU), World Bank Urban Advisory Unit, and a number of university research centres). The SCC provides a number of resources, events and task forces designed to promote smart city ideas and create social learning. 
Similarly, TM Forum (https://www.tmforum.org/) is a large global member association consisting of over 900 members ranging in size from large multinationals to start-ups and university research groups, and also includes some city units such as Smart Dublin. It has a wide remit, promoting the use of digital business in general across government, but has a significant focus on creating smart cities. To this end, TM Forum runs several short and long-term initiatives designed to help advise and guide city management and promote shared knowledge creation and circulation, including: Smart City Global Forum (a global LinkedIn discussion group); Smart City Projects (collaborative assets being collectively produced, including a framework toolkit, best practice guidelines, maturity assessments, benchmarks and catalogues); Smart City InFocus Events (conferences/workshops); Smart City Innovation Centres (development and testing sites); Smart City Hackathons; and a Smart City Think Tank Group (linking together 10 consultancies to develop new ideas and concepts).

In contrast to SCC and TM Forum, which are both heavily dominated by corporate interests, the 'Open \& Agile Smart Cities' (OASC; http://www.oascities.org/) is a global network advocating smart cities based on the needs of cities and communities which adhere to the principles of openness (open source, open standards, open data) and avoidance of vendor 'lock-ins' (being locked into using propriety systems). The aim is to enable interoperability between systems and platforms that boosts civic engagement, innovation and competitiveness. The OASC promotes its message and work through an active programme of events and support for initiatives related to the development of open standards and platforms.

\subsection{Supra-national epistemic community and advocacy coalition}

Working somewhat in parallel with the global networks/coalitions are supra-national, governmental-led policy and programmatic initiatives. This is particularly the case in the European Union where a number of institutional networks and high-level programmes have been driving the smart cities agenda through a set of institutional arrangements, funding schemes, networking events, and conferences and workshops. These networks and programmes, and their strategies and mechanisms, are overseen through management boards and scientific advisory boards primarily staffed by a mix of academic and public sector actors that act as an epistemic community.
For example, 'The European Innovation Partnership on Smart Cities and Communities' (EIP-SCC; https://eusmartcities.eu/) seeks to bring together cities, industry, SMEs, banks, research and other stakeholders in order 'to improve urban life through more sustainable integrated solutions' [6]. The EIP-SCC does this by fostering the 'partnering of public and private actors to co-create a pipeline of projects and share their risks.' By 2015 the EIP-SCC documented 370 commitments (which it defines as measurable and concrete smart city engagements/actions) with 4000 public and private partners from 31 countries. These commitments have received hundreds of millions of euro in investment between them to embed smart city doctrine in city administrations and implement on-theground smart city initiatives. In addition, the EIP-SCC organizes six 'Action Clusters': sustainable districts and built environment; sustainable urban mobility; integrated infrastructures and processes; business models, finance and procurement; citizen focus; and integrated planning, policy and regulations.

Collectively, the Action Clusters form various 'marketplaces' for smart city solutions. Indeed, while the EIP-SCC is driven by a strong commitment to improving the quality of life of urban citizens and producing better and more sustainable places to live, there is also a strong market logic that seeks to increase the 'competitiveness of Europe's industry and innovative SMEs' and to capture a significant portion of the rapidly growing global market for implementing smart city initiatives, which they estimate to be worth $€ 1.3$ trillion. It is perhaps no surprise that the stated ambition of EIP-SCC is to 'overcome market fragmentation and achieve scale in building a market for smart city innovations.' Critically, the EIP-SCC operates a mechanism for sharing and embedding the vision of the smart city epistemic community by: funding new technocrat posts; demonstrating the potential of the smart city vision; and fostering social learning.

There are number of similar inter-related initiatives across the complex web of European bodies that have a focus on cities. These are complemented by a range of funding mechanisms for supporting smart city research, projects, networking, and sharing, that link together academia, city administrations, companies and civil society, such as: H2020; JPI-Urban Europe; European Regional Development Fund; Connecting Europe Facility; Cohesion Fund; European Social Fund; Eureka Smart City; and Community-Led Local Development. 


\subsection{National and local-level epistemic community and advocacy coalition}

While the global and supra-national scales provide a transnational means for the knowledge of epistemic communities and advocacy coalitions to circulate and propagate, it is at the national and local-level that the grounding of their ideas takes place through their embedding in institutional structures, appointment of personnel at different scales of government (e.g., nationallevel departments and agencies, and regional and local/ municipal authorities), and the development of specific policies and deployments.

In the Irish context, there are a number of wellfunded interdisciplinary research institutes and centres that specialise in smart cities research that actively partner with numerous industry collaborators (from multinationals such as IBM, Intel, Huawei, CISCO and Dell to SMEs and startups) and work with Irish cities, including extensive testbedding and trialling. Collectively this constitute a functioning national-level epistemic community. In addition, the recently launched (Dec 2016) 'All Ireland Smart Cities Forum' brings together representatives from seven Irish cities, five from the South (Cork, Dublin, Limerick, Galway, Waterford) and two from the North (Belfast and Derry) to share insights, support collaborative research, and work with stakeholders on collective city priorities. More locally, 'Smart Dublin' and 'Cork Smart Gateway' are local authority initiatives that seek to guide smart city projects within municipal departments and work through public-private partnerships with smart city technology providers to realise initiatives. In both cases, Smart Dublin and Smart Cork Gateway act as entry routes for the epistemic community and local advocacy coalition into the wider institutional structures.

\section{Bridging the 'last mile' problem}

As detailed, over the past decade: a set of smart city professionals have been successfully inserted into city administrations; an active and lively smart city epistemic community and advocacy coalition has been formed at different scales; an extensive and diverse apparatus of social learning has been rolled out; and in many cases funding opportunities to support smart city initiatives have been created enabling numerous initiatives to be deployed. However, while smart city policy and programmes are being implemented in many cities, it is clear that, with a couple of exceptions that have unique characteristics (such as Songdo in South Korea [19] and Masdar in United Arab Emirates [3] that are new cities built on greenfield sites), they are fragmented in nature and the smart city vision is only partially embedded within city administrations at present. Consequently, the ideas, policies and technologies of the smart city movement have only gained partial traction in driving how city bureaucracies manage and govern their jurisdictions and approach tackling urban issues. Moreover, they are being greeted with apathy or resistance by some staff and citizens. In other words, it seems that promoters and technocrats of the smart city vision are having difficulty 'bridging the last mile' from theory and vision to fully mainstreamed policies and adoption across organizations. Here, we want to consider the reasons for these 'last mile' difficulties in ameliorating the work of epistemic communities and advocacy coalitions.

City administrations are to a degree like an oil tanker. They are large, complex organizations consisting of many departments, with entrenched structures, ways of working, and established legacy systems that create a high degree of embedded path dependency. They are also full of internal politics, fiefdoms, and competing interests. As such, they are not easy to reorientate with respect to shifting how units and staff think about and undertake their work, especially when they directly challenge the paradigmatic training and ideals of professionals schooled to think and act in certain ways (e.g., planners, engineers, architects, educators, social workers, community development workers). A smart city approach promises to create a more nimble, flexible, data-driven, efficient, horizontal organization, cutting across departmental silos and enabling joined-up responses to urban issues. They thus promise to disrupt the status quo and radically change working conditions, including leading to redundancies.

Smart city ideas and policy thus run into internal inertia and resistance by both managers and workers. In addition, they can run into external critique from academics, NGOs, community groups, and politicians, who hold different views as to the supposed benefits and underlying ideology of the smart city agenda [4, 9, 11, 14, 17, 21]. Part of the critique of the smart city epistemic community is that while they claim to be able to tackle perceived problems, they have a limited perspective shaped by their disciplinary expertise and lack sufficient grounded domain knowledge of an issue [15], often treating the city as a technical system as opposed to a multifaceted place. The result is a form of technological solutionism in which digital technologies are positioned as the answer to all issues, regardless of context and history. Consequently, there has been a marked push-back against the ideas and ideals of the smart city in recent years, especially concerning the role of citizens, the technocratic nature of governance and 
its instrumental rationality, and the marketization of public services $[4,9,14,17]$. While the smart city movement has targeted city administrations with some success, it has had less engagement with local politicians and the public, and has largely ignored alternative academic views other than to counter with a call for citizen-engaged smart cities (which tends to be limited to user-feedback rather than bottom-up ownership and participation) [2, 9].

Fuelling resistance and doubts is a sense that the majority of smart city technology is not yet mature and unsuitable for mainstreaming. Technologies are still being developed and tested. They are like drugs in the clinical trial phase. This is borne-out in the large number of pilot projects and what has been termed 'experimental' or 'testbed' urbanism or 'living labs' [7]. Practically all EU-funded smart city projects have this status, being initiatives to scope-out, produce and implement proof-ofconcepts, and share knowledge about efforts, rather than being market-ready and proven to work in practice. Moreover, it is fair to say that, as with other epistemic communities and advocacy coalitions, there is some diversity of views within them, as well as a structure and power dynamics as to who is shaping and driving the agenda. As such, while there is a general consensus on the utility of digital technologies for tackling urban issues, there is not universal agreement on the form of technical solution or related factors such as the role of citizens in shaping how issues are tackled [2, 9, 21]. In other words, smart city ideas and technology are still very much in development phase and investing in them poses a risk for city administrations charged with providing stability, certainty, and reliability in the delivery of city services.

Fostering scepticism is a lack of trust among many city administrators as to whether a smart city approach will work in practice. Cities have a long history of purchasing technologies that are costly and do not always deliver on their promises. This includes the first wave of smart city products sold to them that bound them into unfavourable contracts and supplied technical solutions that did not deliver on their promises. One consequence is that cities are becoming more savvy with respect to procurement in order to ensure that they do not lose control of a service or associated data/IP and that companies provide the service desired.

An additional concern relates to financing and the amount of perceived value for money spent and the return on investment. Many smart city solutions are expensive to procure and service, yet it is not always clear what the return on investment will be beyond promises that a service will improve or an issue be ameliorated in some way. Moreover, it is clear that the same technology will be cheaper and better - in terms of spec, functionality, performance - in a few years, so it is difficult to know when to make the initial investment. Many cities are currently operating in a condition of austerity, so finances for new investments are constrained. As such, although some technologies could save the city money over the long term, the city still must find the initial investment capital. This is why so much effort is now being expended on new business models for smart city investments. Another issue is competing demands for finance with a limited budget. Many services are statutory obligations and unless the smart city technology can address these critical issues, they will have trouble competing for attention and resources.

\subsection{Smart lighting in Dublin}

Many of these concerns were exemplified in research conducted in 2015 on the possible implementation of smart lighting in Dublin, and on the potential of a Central Management Systems (CMS) to give a higher degree of control and flexibility over lighting by converting it into digitally networked infrastructure [8]. Smart Lighting seeks to augment the existing lighting infrastructure by making it a digital network with uniquely addressable LED bulbs which can be individually dimmed and trimmed, with the pole and network supporting additional services such as real-time sensor arrays (e.g., to monitor air quality, noise, parking spaces), CCTV cameras, digital screens for communication/advertising, and public wifi access.

The smart lighting agenda was being driven by an advocacy coalition of consultancies, vendors and Smart Dublin who were utilising supra-national concerns relating to climate change and reduction of $\mathrm{CO}^{2}$ levels, drawing on European 2020 directives, to lobby for the introduction of LED lighting with a CMS, and national concerns relating to economic recovery after a severe financial crash to press the need to attract ICT companies to key strategic zones such as Dublin's 'Silicon Docks' by facilitating urban experimentation and testbedding [7]. The needs of citizens or the promotion of citizen engagement related to lighting was largely absent from this endeavour. Instead, the coalition worked to bypass citizen and political scrutiny, positioning their alliance as an informal meeting of minds:

'it just happened that we got connected with [Consultancy firm] at a few different events. It turns out a couple of their staff are Irish people working in the UK and are particularly interested in connecting in for the benefit of Ireland Inc., as well as maybe their own benefit as well.' (Smart Dublin representative) 
In this context, the scoping study focussed on the potential benefits and costs of smart lighting and the possible impact on existing infrastructure and workers. Several barriers to implementing smart lighting were identified including: creating interaction issues with citizens over the control of lighting; limits to the efficacy of CMS; the future role of the lighting team in the local authority following implementation (including retraining or job losses); potential issues with retrofitting lights and the current electrical infrastructure in Dublin; costs with updating the lighting infrastructure to accommodate new services; additional risks incurred from employing complex systems; data processing and analysis issues; and scepticism as to the potential cost savings. For example, with regards to the latter, senior managers questioned the efficacy of smart lighting for realising cost reductions. On the one hand, it was recognized that significant savings in costs and $\mathrm{CO}_{2}$ emissions would be achieved by switching to LED lights without a CMS:

'So it is very easy for a local authority to install an LED now and get maximum effect in terms of energy savings and you will get that from the month you put that in you will start to achieve those savings.' (Utilities representative)

On the other, the initial infrastructure costs for updating the network to accommodate CMS would be so enormous that they would nullify any benefits:

'Listen, there will be savings but they will not be savings over the extra cost that you would have been paying. So if you look at it in real terms, there is probably no saving in public lighting because there has been so little investment in it for a number of years, columns need to be replaced [as well as cabling and ducting], so anything that you are saving on the energy side you will have to put back into investing in new infrastructure' (Senior Civil Servant, Dublin City Council).

The lighting department of Dublin City Council currently manages 45000 lighting units. The current thinking behind any systems upgrade is to address the statutory obligations of public lighting at the best price for the authority, not to address any 'smart city' solution that might be facilitated through advanced CMS usage:

'Cost wise, we are after doing the tender now and the replacement for those lamps would be about $€ 250$ each. They are not that expensive, that is a pretty good price. But we would intend to roll those LEDs out with pre-programmed dimming [that is, without the ability to be controlled from a distance]. That is what we do.
And that is basically where we stand.' (Senior Lighting Engineer, DCC).

There is also a worry concerning the accumulated risks from implementing CMS and upgrading infrastructure (poles, cabling, etc.):

'Your question about the central management system, I think that is another new innovation and again there is a risk involved in that and I think this has got to be taken into account. So if you have one risk, a certain amount, if you have a second one at the same time, it is the square of the risk, so it is four times the risk for two innovations and nine times for three, a square law rather than a linear one.' (Representative of an environmental agency)

In addition, a smart city advocate inside the organization noted that it was difficult to drive change internally:

'Obviously there is a huge knock-on benefit for industry if we are more proactive in terms of our assets. So that is an ongoing piece because one of the challenges is internally there is a huge resistance to looking at anyone touching any of these assets in a way that can drive new opportunities. So that is a key one because it is fine for me to present internally and say I think we should be doing this. And people are like, who the hell are you? You are just an upshot that has rolled in and you are telling us what to do.' (Project worker, DCC)

Instead of a city-wide roll-out, Dublin is continuing to develop small-scale deployments that satisfy the economic development aims of the advocacy coalition. One example is in the Dublin Docklands, itself considered as a 'smart district' for trialling a number of other new technologies such as a smart grid, e-mobility, and environmental sensors. The roll-out of smart lighting in the Docklands responds both to more prosaic fundamentals such as the fact that local lighting is metered unlike elsewhere in the city, and to the medium to long-term goals of ensuring the area showcases the modern and creative capital city as a desired location for investment and locating employment. Within the smart district, lighting is seen as both a key utility infrastructure and as a platform for deploying other smart technologies (such as Wi-Fi, sensor deployments, public communication signs, CCTV). While the potential is there to upscale after test-bedding in the Docklands, the agency of the advocacy coalition in the rest of the city region is less powerful, hindered by political resistance to market intrusion, limited budgets for infrastructure and public sector personnel, and institutional and procedural inertia. Perhaps unsurprisingly, city managers gener- 
ally prefer to exploit the second-mover advantage-that is, the advantage of knowing the system will work in solving a particular problem and improve city services. For example, if city management is going to upgrade 45000 lampposts to smart lighting, they want to be confident that the system is going to work well and do what was promised. They do not want a newspaper headline that states, " $€ 15$ Million of Taxpayers' Money Wasted".

In addition, the epistemic communities and advocacy coalitions coalescing around the field of smart cities seem to little appreciate the need for democracy, openness and public consultation in city management: mostly, executive decisions are made outside of democratic process and city managers green-light smart city projects with little political, media or public oversight or feedback. In the case of Dublin, local politicians and the public have been ignored almost entirely in the formulation of Smart Dublin and the development and rollout of smart city initiatives. Indeed, nearly all decisions for selecting and implementing smart city initiatives seem to have bypassed public consultation and political debate. As such, the focus of the epistemic community and advocacy has been exclusively targeted at the city bureaucracy. This is perhaps no surprise given that the city has no mayor and is largely run by the CEOs of the four local authorities.

\section{Conclusion}

We have argued in this paper that over the past decade a sizeable and influential smart city epistemic community and advocacy coalition has developed at multiple scales. In a short space of time a new cadre of smart city technocrats - CIOs, CTOs, CDOs, data scientists, designers, policy specialists, software engineers, and project managers - has been appointed to roles in city administrations, organizational structures have been re-jigged to accommodate them, and a raft of new smart city initiatives has been implemented. These technocrats are working with, and supported by, a panoply of external professionals within institutional bodies, academia and companies, who provide a range of services and enact social learning through consultancy, professional development training, conferences and workshops, co-operation in project work, and hackathons. While there are communities of scholars and 'expert amateurs' that forward an alternative vision of smart cities, particularly a version that is more citizen-focused, -engaged or -run, the dominant paradigm of smart cities is still rooted in a technocratic formulation, albeit one that now acknowledges the need for citizen par- ticipation though very much from a civic paternalist or stewardship perspective.

Collectively the smart city epistemic community and advocacy coalition is starting to reshape urban policy, how funding is distributed and spent, and how city government works, including aiding its marketisation. However, due to a number of issues - not least of which is the relative immaturity of the policy and technical solutions being offered, along with institutional inertia - smart city ideas and ideals have only become partially embedded in city administrations. In effect, while the smart city movement has captured some of the bureaucratic and political terrain at local, national and supra-national scales (e.g., some mayors, some government departments, and various EU bodies) it has a 'last mile' problem in many cities.

The extent of this last mile issue varies between municipalities and cities. For example, in Rio de Janeiro the city's control room draws together 32 agencies and 12 private companies into one shared facility producing strong horizontal collaboration [16]. In most other cities, control rooms tend to still be single domain in nature, focusing solely on managing one service (e.g., traffic, telecoms, fire service). In the Boston Metro Area, the City of Boston has embraced the notion of a smart city, employing over 40 data and smart city specialists within the organization (including a CIO and CDO), creating new units and structures (such as the Citywide Analytics team and New Urban Mechanics), and adopting new forms of data-driven performance management. However, the other 100 municipalities in the Boston Metro Area have only a handful of new smart city technocrats and relatively few initiatives underway. Similarly, the four Dublin local authorities vary in their investment in new personnel and participation in smart city initiatives. However, beyond Smart Dublin, none have made changes to their organizational structures, and many of the staff involved in Smart Dublin are quite junior and have limited power to enact change. Collectively, the LAs are experimenting with using procurement by challenge, but on single issues such as increasing the modal share of bicycle use rather than wholesale infrastructure concerns.

The challenge then for smart city advocates is to bridge this 'last mile', persuading key decision-makers that the smart city approach to managing cities and tackling urban issues through digital technology solutions will radically improve the lives of citizens and help businesses thrive. For this to occur, they need to continue to further enhance the reputation of the epistemic community, strengthen the advocacy coalition, capture more bureaucratic positions, demonstrate the utility of their proposed approach, win the ideological argument over the marketization of city ser- 
vices, and deliver proven, mature, dependable solutions. For those opposed to the notion of a smart city as presently conceived, the challenge is to either re-orientate the imaginaries and logics of the smart city $[15,21]$ or to offer an entirely alternative view of how cities should be run and managed and urban issues tackled, one rooted in a different set of politics and ideology (e.g., rights, citizenship, participation) $[2,9]$. These are the battle lines for the next few years.

The smart city epistemic community and advocacy coalition shows no signs of abating, but rather is continuing to grow as ever more technical and scientific academics (e.g., engineers, computer scientists, data scientists, physicists, mathematicians) and companies turn their attention to urban issues and cities further embrace technological solutions to urban management and governance. Those opposing their ideas and ideals show few signs of becoming less entrenched in their critique and the last mile issues we detail will not dissipate overnight. How this will ultimately play out is difficult to pre-determine, but it is fair to say that the new technocrats are unlikely to be leaving city government any time soon, many ICT solutions already deployed are embedded in city governance (e.g., intelligent transport systems) and unlikely to be decommissioned, and large investment is being ploughed into developing and trialling new technology for deployment across domains (e.g., transport, energy, economy, environment, homes).

Acknowledgement: The research for this paper was provided by a European Research Council Advanced Investigator Award, 'The Programmable City' (ERC-2012-AdG323636).

\section{References}

1. Michael Batty (2013) Urban Informatics and Big Data. London: CASA, University College London, http://www. spatialcomplexity.info/files/2015/07/Urban-Informaticsand-Big-Data.pdf Accessed 2017-1-2.

2. Paolo Cardullo and Rob Kitchin (2017) Being a 'citizen' in the smart city: Up and down the scaffold of smart citizen participation. Programmable City Working Paper 30, https:// osf.io/preprints/socarxiv/v24jn.

3. Federico Cugurullo (2013) How to build a sandcastle: An analysis of the genesis and development of Masdar City. Journal of Urban Technology 20(1): 23-37.

4. Ayona Datta (2015) New urban utopias of postcolonial India: 'Entrepreneurial urbanization' in Dholera smart city, Gujarat. Dialogues in Human Geography 5(1): 3-22.
5. Christine Dunlop (2013) Epistemic communities. In M. Howlett, S. Fritzen, W. Xun, and E. Araral (eds) Routledge Handbook of Public Policy. Routledge.

6. European Commission (2015) Smart cities and communities, http://ec.europa.eu/eip/smartcities/ Accessed 2017-5-15.

7. James Evans, Andrew Karvonen and Rob Raven (eds) (2016) The Experimental City. Routledge.

8. Leighton Evans and Darach MacDonncha (2015) Report on public lighting and smart lighting in Dublin. Programmable City, Maynooth. Unpublished report.

9. Marcus Foth, Martin Brynskov and Timo Ojala (Eds) (2015) Citizen's Right to the Digital City: Urban Interfaces, Activism, and Placemaking. Springer, Singapore.

10. Jennifer Gabrys (2014). Programming environments: Environmentality and citizen sensing in the smart City. Environment and Planning D: Society and Space 32 (1): 30-48.

11. Adam Greenfield (2013) Against the Smart City. Do Publications.

12. Peter Haas (1992) 'Introduction: epistemic communities and international policy coordination', International Organization 46(1): 1-35.

13. Peter Haas (2001) 'Policy knowledge: epistemic communities' In N. J. Smelser \& B. Baltes (eds.), International Encyclopedia of the Social and Behavioral Sciences vol 17: 11578-11586.

14. Rob Kitchin (2014) The real-time city? Big data and smart urbanism, GeoJournal, 79(1): 1-14.

15. Rob Kitchin (2016) Reframing, reimagining and remaking smart cities. Programmable City Working Paper 20, https://osf.io/cyjhg/.

16. Andres Luque-Ayala and Simon Marvin (2016). The maintenance of urban circulation: an operational logic of infrastructural control. Environment and Planning D: Society and Space 34(2): 191-208.

17. Shannon Mattern (2014) Interfacing urban intelligence. Places: Design Observer http://places.designobserver.com/ feature/how-do-we-interface-with-smart-cities/38443/ Accessed 2014-7-17.

18. Paul Sabatier and Hank Jenkins-Smith (1993) Policy Change and Learning: An Advocacy Coalition Approach. Westview Press.

19. Sofia Shwayri (2013) A model Korean ubiquitous eco-city? The politics of making Songdo. Journal of Urban Technology 20(1): 39-55.

20. Martin Tironi and Tomas Criado (2015) Of sensors and sensitivities. Towards a cosmopolitics of 'Smart Cities'? Tecnoscienza: Italian Journal of Science \& Technology Studies 6(1): 89-108.

21. Anthony Townsend (2013) Smart Cities: Big data, civic hackers, and the quest for a new utopia. W. W. Norton \& Co.

22. Anthony Townsend (2015) Making Sense of the New Science of Cities. Rudin Center for Transportation Policy \& Management and Data and Society Research Institute, New York University. http://www.citiesofdata.org/wp-content/uploads/2015/04/ Making-Sense-of-the-New-Science-of-Cities-FINAL-2015.7.7.pdf Accessed 2017-1-2.

23. Anja Wejs (2014) Integrating climate change into governance at the municipal scale: An institutional perspective on practices in Denmark. Environment and Planning C: Government and Policy 32(6): 1017-1035. 


\section{Bionotes}

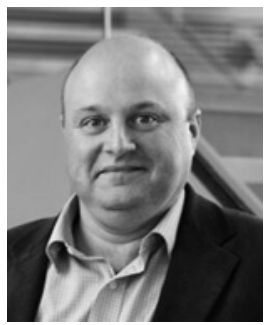

\section{Rob Kitchin}

NIRSA, Maynooth University, Iontas

Building, W23 F2H6, Maynooth, Ireland rob.kitchin@mu.ie

Rob Kitchin is professor and ERC Advanced Investigator at the National University of Ireland Maynooth. He is (co)principal investigator of the Programmable City project and the Building City Dashboards project. He has published widely across the social sciences, including 26 authored/edited books and over 180 articles and book chapters. He was the editor-in-chief of the 12 volume, International Encyclopedia of Human Geography, and is presently editor of the journal, Dialogues in Human Geography. He was the 2013 recipient of the Royal Irish Academy's Gold Medal for the Social Sciences.

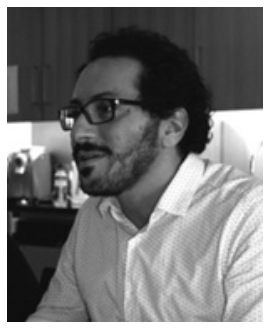

\section{Claudio Coletta}

NIRSA, Maynooth University, Iontas Building, W23 F2H6, Maynooth, Ireland claudio.coletta@mu.ie

Claudio Coletta is a Postdoctoral Researcher at the National Institute for Regional and Spatial Analysis (NIRSA), Maynooth University. He works as part of the ERC funded Programmable City Project. His research focus is on urban phenomena at the intersection between technology, narratives, practices, explored through qualitative methods. His current interests address algorithms and automated urban management, temporal dimension of smart city development, experimental urbanism and procurement.

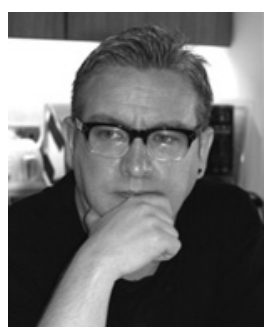

\section{Leighton Evans}

Media and Communications, Swansea University, SA2 8PP, Swansea, Wales, United Kingdom of Great Britain and Northern Ireland

Leighton Evans is a Senior Lecturer in Media Theory at Swansea University, having previously been a Postdoctoral Researcher at the National Institute for Regional and Spatial Analysis (NIRSA), Maynooth University. His research focus is on phenomenology and digital media, with interests in locative media, virtual and augmented reality, the experience of labour in data intensive environments and the subjective experience of technological implementation.

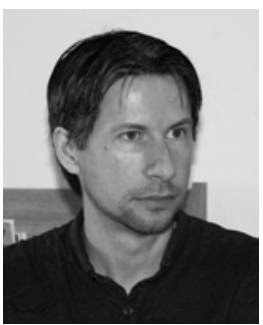

\section{Liam Heaphy}

NIRSA, Maynooth University, lontas

Building, W23 F2H6, Maynooth, Ireland

Liam.Heaphy@mu.ie

Liam Heaphy is a Postdoctoral Researcher at the National Institute for Regional and Spatial Analysis, Maynooth University, working on the ERC-funded Programmable City Project. He has a background in social sciences, with an interest in science and technology studies, architecture and history, and languages. His research is on the relationship between urban science and urban form, covering smart city technologies and climate change. He has worked and studied at the University of Manchester, as well as the University of Salamanca, Spain and the médialab of Sciences Po, Paris.

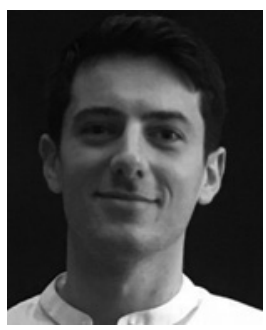

Darach MacDonncha NIRSA, Maynooth University, Iontas Building, W23 F2H6, Maynooth, Ireland darach.macdonncha.2014@mumail.ie

Darach MacDonncha is a doctoral student at the National Institute for Regional and Spatial Analysis, Maynooth University, working on the ERC-funded Programmable City Project. He has a BA in Geography and Irish from National University of Ireland, Galway and a MA in Geopolitics and the Global Economy from University College Dublin. His research is focused on the adoption of digital technologies by city administrations and the political economy of smart cities. 